\title{
ANÁLISE MULTITEMPORAL DA OCUPAÇÃO IRREGULAR DAS MARGENS DO RIO 40 HORAS NO MUNICÍPIO DE ANANINDEUA-PA
}

\author{
Yuri Alefh Saraiva Dias ${ }^{(a)}$, Gierre Martins de Sousa Júnior ${ }^{(\mathrm{b})}$, Ney Leonardo Silva Soares ${ }^{(\mathrm{c})}$, \\ Gabriel dos Santos ${ }^{(\mathrm{d})}$.
}

(a) Faculdade de Tecnologia em Geoprocessamento, Universidade Federal do Pará, yurifurtado35@gmail.com

(b) Faculdade de Tecnologia em Geoprocessamento, Universidade Federal do Pará, gierremartins@ gmail.com

(c) Faculdade de Tecnologia em Geoprocessamento, Universidade Federal do Pará, neysoares81@ gmail.com

(d) Faculdade de Tecnologia em Geoprocessamento, Universidade Federal do Pará, gabriel.santos@ig.ufpa.br.

Eixo: Uso e ocupação das terras e legislação ambiental

\begin{abstract}
Resumo
O Rio 40 horas situa-se no subsistema hidrográfico do Ariri, na região metropolitana de Belém, no município de Ananindeua no estado do Pará, abrangendo três bairros: Cidade Nova, 40 horas e IcuíGuajará. O Objetivo do trabalho é fazer uma análise multitemporal da área de estudo, apresentando o levantamento de impactos produzidos na drenagem decorrentes das ocupações e uso do solo que são constatadas na paisagem do município, como a retirada da vegetação, além da ocupação nas margens do rio por condomínios habitacionais, comércios e casas, que contribuem para a degradação do ambiente, ocasionando então o assoreamento e poluição do rio. Foram utilizados softwares, e imagens do Google Earth para analisar o ambiente a fim de mostrar o uso das terras, fazendo uma análise temporal de 20 anos, para a obtenção dos resultados. Concluindo, notamos que os usos das ferramentas digitais de processamento GIS são de extrema importância para a gestão e ordenamento territorial.
\end{abstract}

Palavras chave: Ocupação do solo; Assoreamento; Poluição; Subsistema hidrográfico do Ariri;

\section{Introdução}

O crescimento da população de Ananindeua, a falta de infraestrutura, planejamento e supervisão dos órgãos competentes, resulta na ocupação desordenada das margens do rio Ariri, impactando no uso das terras, despejo irregular de esgoto doméstico, retirada da mata ciliar, erosão e assoreamento dos rios.

De acordo com o último censo demográfico de 2010, o município de Ananindeua, inserido na região metropolitana de Belém, apresentou um aumento significativo na sua população (IBGE, 2015). No que vem influenciando a dinâmica dos sistemas ambientais locais, principalmente nos pequenos corpos d'água, que vem sofrendo maior pressão. Junto a esse problema registra-se a má gestão dos recursos hídricos e uma deficiência na distribuição desse recurso para população local. As ocupações irregulares em áreas próximas de corpos d'água, os usos e manejos inadequados dos solos são características da falta de um planejamento urbano pouco eficaz de um município, isso vem fazendo com que os processos 


\section{OS DESAFIOS DA GEOGRAFIA FÍSICA NA FRONTEIRA DO CONHECIMENTO \\ Instituto de Geociências - Unicamp \\ Campinas - SP \\ 28 de Junho à 02 de Julho de 2017}

degradacionais sejam instalados em ambientes naturais, de forma que muitos são praticamente impossíveis de serem revertidos.

Segundo Constantini (2012), uma bacia hidrográfica pode sofrer mudanças ambientais devido a muitos fatores, bem como perturbações antrópicas como mudanças no uso e ocupação da terra, desenvolvimento urbano, fragmentação florestal, entre outros.

Padilha (2008) considera que as ferramentas de geoprocessamento são essenciais na análise da fragilidade ambiental, pois permitem que sejam realizadas análises, planejamento e monitoramento de áreas naturais, permitindo assim simulações e estabelecimento de intervenções das melhores alternativas.

Como metodologia, foi realizada uma análise multitemporal das APPs do Rio 40 horas a partir de imagens no programa Google Earth Pro no período de 1995 a 2015, com o propósito de identificar ocupações irregulares em APPs nas faixas marginais do Rio 40 horas, segundo o que determina a resolução da CONAMA n 303/2002. Para atingir o objetivo proposto, fez-se necessária a integração e elaboração de produtos cartográficos para localizar e também quantificar o aumento das ocupações irregulares nestas áreas.

\section{Caracterização da área de estudo}

A área de estudo que compreende o subsistema do Ariri está localizada no município de Ananindeua, na região metropolitana de Belém, no estado do Pará. O rio 40 Horas possui aproximadamente 3,7 km de extensão total, o trecho estudado é formado por uma nascente e um curso d'água de aproximadamente 1,5 $\mathrm{km}$ na qual deságua no rio maguari, influenciando três bairros do município de Ananindeua: Cidade nova, 40 horas e Icuí-Guajará. Conforme apresentado na figura 1. 


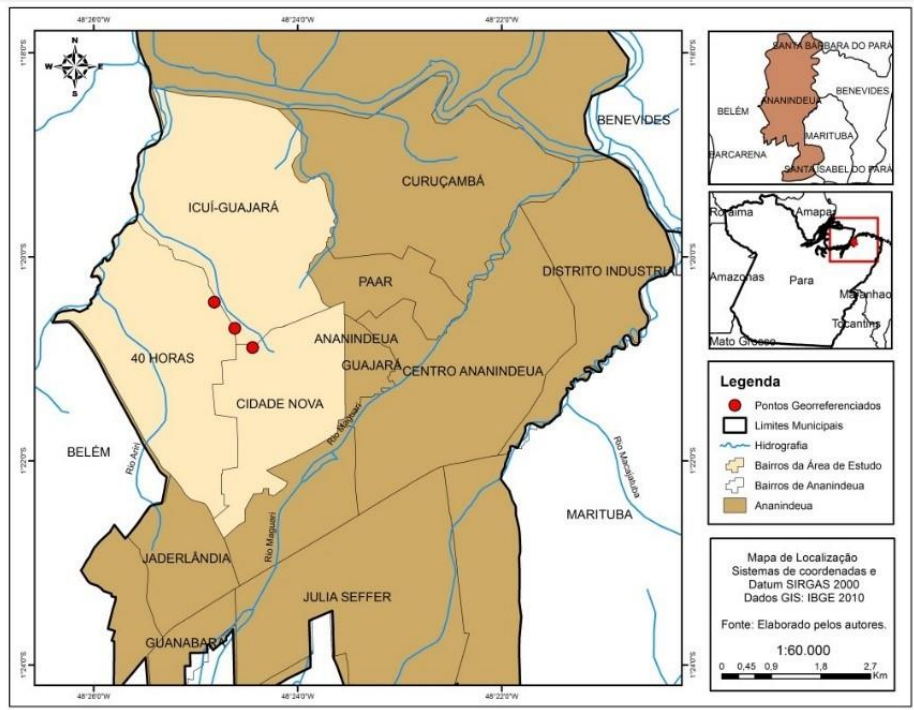

Figura 1: Localização geográfica da área de estudo. 


\section{Materiais e métodos}

Para um melhor planejamento e visualização da área de estudo, optou-se por utilizar o programa com licença para estudante Google Earth Pro ${ }^{\circledR}$ v6. 2.2.6613 (Google), por possuir um banco de dados bem atualizados e imagens de boa qualidade, o que possibilitou uma delimitação mais detalhada de um polígono na área estudada, com intuito de facilitar os cálculos das áreas de ocupação no entorno do rio, nos anos de 1995 e 2015, em seguida exportado, no formato "shapefile" (. shp), para o software ArcGIS $10.3^{\circledR}$ (ESRI, 2015). Foram coletados três pontos, in loco, no dia 07 de dezembro de 2016, para um futuro georreferenciamento local, com auxílio de um GPS de navegação GARMIN, modelo ETREX 10, configurado com o DATUM WGS 1984, que apresentou margem de erro de 5 metros. O polígono foi confeccionado medindo 1.408.000 $\mathrm{m}^{2}$. Delimitou-se a área de proteção permanente (APP) da drenagem e nascente utilizando a ferramenta "buffer" do programa $\operatorname{ArcGIS}^{\circledR}$ 10.3. Os valores adotados na ferramenta "buffer" seguiram a resolução da CONAMA (Conselho Nacional do Meio Ambiente) nº 303/2002, onde se estabelece um limite de raio de 15 metros para o entorno do rio, e 50 metros para o entorno da nascente, para o curso d'água com menos de dez metros de largura.

\section{Resultados e discussão}

Após a confecção do mapa referente ao avanço das ocupações no entorno do rio 40 Horas (figuras 2 e 3), obteve-se o valor da área de ocupação urbana que no ano de 1995 era de aproximadamente $914.815 \mathrm{~m}^{2}$, onde $155 \mathrm{~m}^{2}$ encontram-se nas áreas de preservação no entorno do rio. No ano de 2015 a área de ocupação passa a ser de aproximadamente $1.069 .000 \mathrm{~m}^{2}$, onde $15.048 \mathrm{~m}^{2}$ desta encontram-se nas áreas de preservação. De acordo com os valores obtidos estabeleceu-se um crescimento de aproximadamente 9.708\% da área de ocupação. A área de preservação permanente (APP) nos arredores dos cursos d'água do rio 40 Horas no ano de 1995 era de aproximadamente $492.803 \mathrm{~m}^{2}$, que equivalia a $35 \%$ da área total abordada. Já no ano de 2015, esta mesma APP passa a ter aproximadamente $338.448 \mathrm{~m}^{2}$, equivalente a $24 \%$ da área delimitada. Obteve-se também, seguindo os métodos de análise, uma área de proteção permanente (APP) de aproximadamente $77.906 \mathrm{~m}^{2}$, a qual foi representada no mapa como sendo a área do buffer, que seguiu as regras da resolução da CONAMA no 303/2002. Pode-se observar que no ano de 1995, a APP possuía 0,2\% de sua área total ocupada de forma irregular, passando a ser de $19 \%$ no ano de 2015. Dessa forma observa-se um processo de ocupação do solo alterando a área significativamente e por este motivo, foi realizado o mapeamento e análise do conflito na área, chegando a uma pré-suposição de que seguindo o ritmo de crescimento atual, pode-se estimar um valor de crescimento da ocupação 


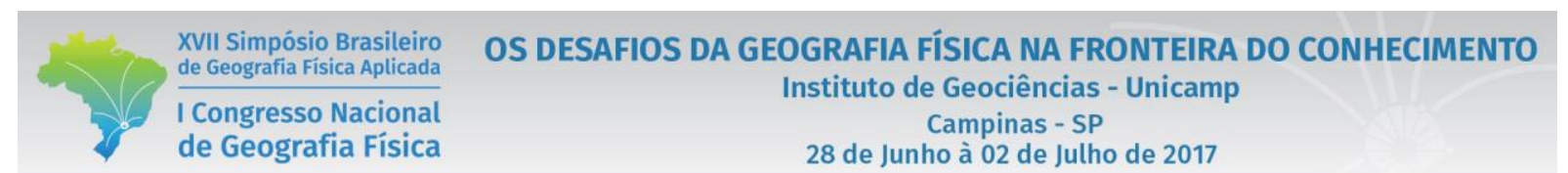

irregular de aproximadamente $745 \mathrm{~m}^{2}$ por ano. Resultando em, aproximadamente, $18.783 \mathrm{~m}^{2}$ de ocupação irregular no ano de 2020, equivalente a $24 \%$ da APP.

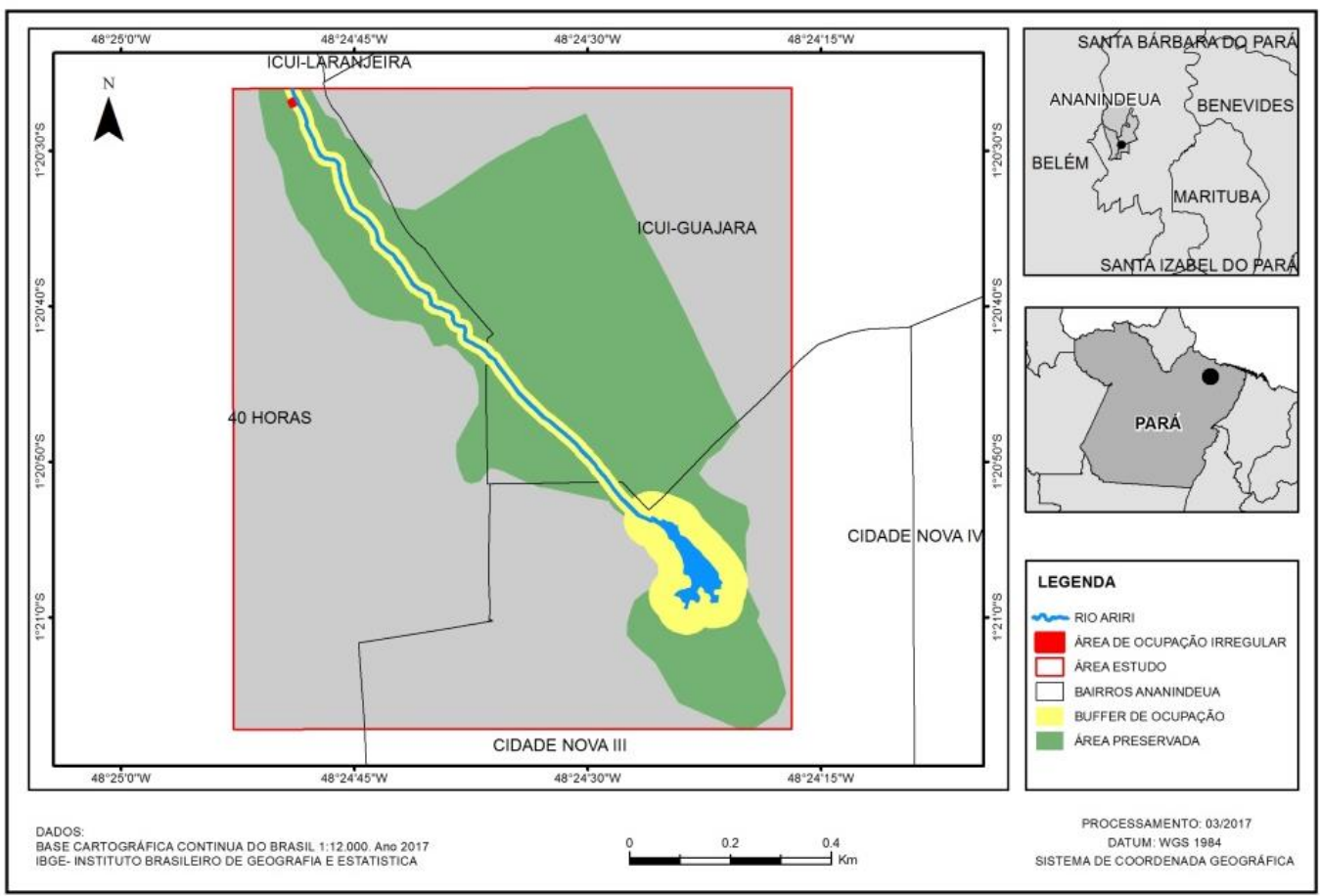

Figura

Área

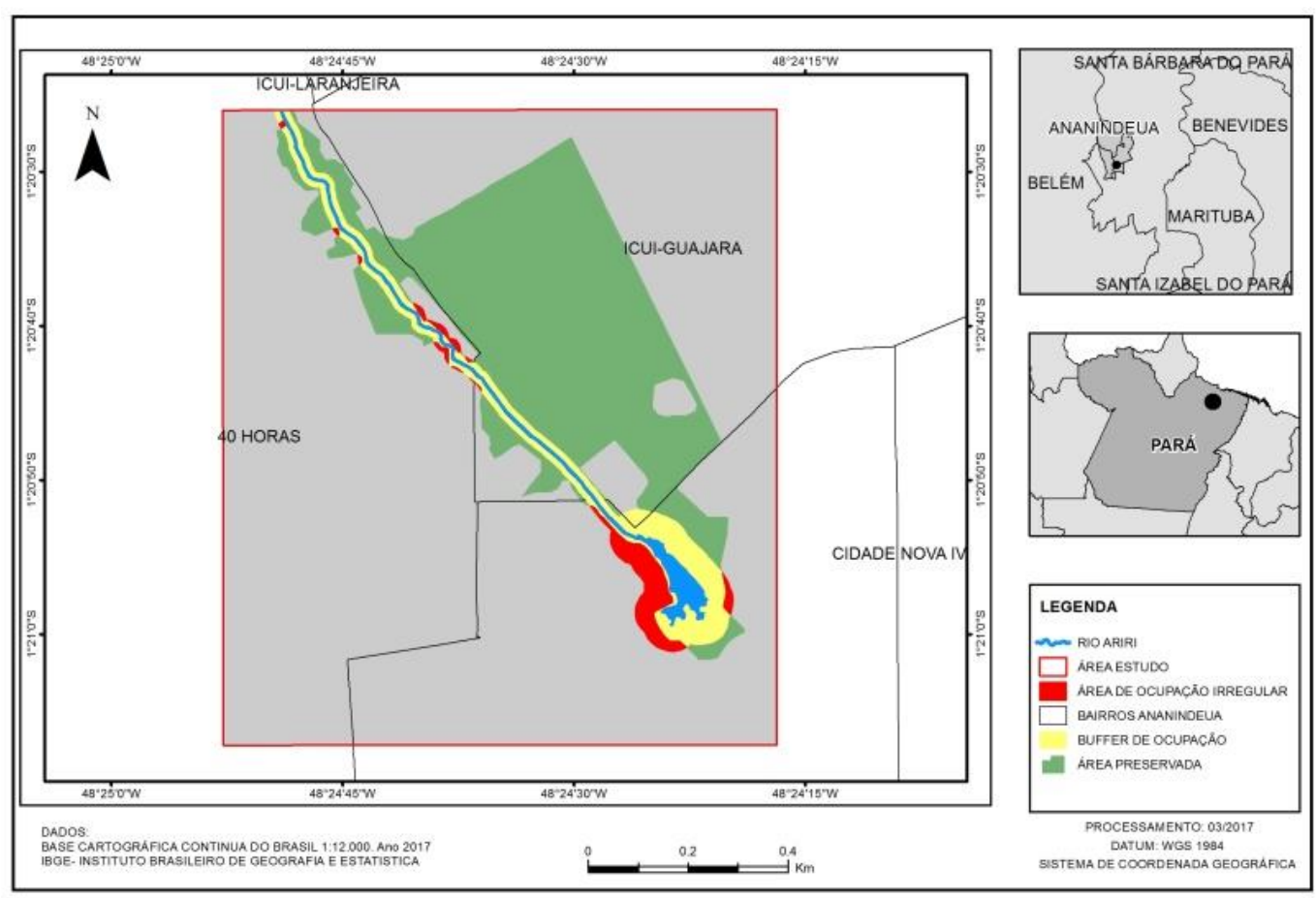

Figura 3: Área ocupada no ano de 2015. 


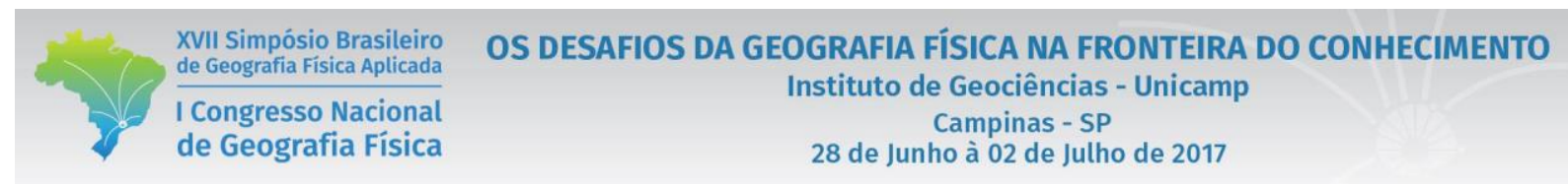

ocupada no ano de 1995. 


\section{Considerações finais}

Os processos de ocupação no entorno do rio 40 Horas tiveram um crescimento significativo ao longo dos anos, como consequência de combinações de vários fatores naturais e antrópicos, os quais também se relacionam com o crescimento populacional, resultando no significativo decréscimo da cobertura vegetal e diversos impactos no local, os quais relacionados à criação de conjuntos habitacionais irregulares. Através dos dados obtidos pode-se constatar a importância de se implementar, na área, um plano de manejo de uso e ocupação sustentável e um melhor gerenciamento dos recursos naturais. Portanto é de vital importância preocupar-se com o ordenamento dos recursos que ainda restam e atentar ao fato, de que estes sejam utilizados de forma racional visando a sua preservação. Apesar da constatação da ação antrópica, que gera todos estes impactos ambientais, não são determinantes para o desaparecimento ou dano causado ao meio, desde que seja realizado respeitando os limites do ambiente na tentativa de chegar a um determinado patamar de equilíbrio entre homem e natureza.

\section{Bibliografia}

COELHO, André Luiz Nascentes. Geomorfologia fluvial de rios impactados por barragens-Fluvial Geomorphology Of Rivers Impacted From Dams. Caminhos de Geografia, v. 9, n. 26, 2008.

CONAMA, Resolução. 357, de 17 de março de 2005. Conselho Nacional do Meio Ambiente-CONAMA, v. 357, 2005.

COSTANTINI, Maria Letizia et al. NDVI spatial pattern and the potential fragility of mixed forested areas in volcanic lake watersheds. Forest Ecology and Management, v. 285, p. 133-141, 2012.

DE OLIVEIRA, Josafá Ribeiro et al. Potencialidades De Águas Subterrâneas No Município De Ananindeua. Águas Subterrâneas, 2001.

DEMOGRÁFICO, IBGE Censo. Disponível em:<http://www. ibge. gov. br >. Acesso em 10 de outubro de 2016, v. $1,2005$.

ESRI. Environmental Systems Research Institute. ArcGIS 10.3. Disponível em: <http://www.esri.com/news/arcnews/spring12articles/introducing-arcgis-101.html>. Acesso em: 10 de outubro de 2016.

GOOGLE EARTH. Earth Pro Store. Disponível em: <HTTPS://earthprostore. appspot.com/productview. ep?pID=COEPRONEW $>$. Acesso em 08 de outubro de 2016.

INPE. Instituto Nacional De Pesquisas Espaciais. Disponível em: <http://www.dgi.inpe.br/siteDgi/portugues/index. php>. Acesso em: 10 de outubro de 2016.

PADILHA, Damáris Gonçalves. Geoprocessamento aplicado na caracterização da fragilidade ambiental da bacia hidrográfica do Arroio Grande, RS. 2008. Tese de Doutorado. Dissertação de Mestrado, Departamento de Matemática, Universidade Federal de Santa Maria, Santa Maria.

PIMENTEL, M. A. da S. et al. Análise Preliminar De Impacto Ambiental Nas Nascentes Do Rio Maguariaçu Ananindeua - Pa. 2006

QUARESMA, J. B. Diagnóstico dos Resíduos Sólidos da Cidade de Monte Alegre - Belém: CPRM/Primaz, 1998. 40. Il. 